\title{
From Global to Local: strengthening district health systems management as entry point to achieve health-related sustainable development goals
}

\author{
P Tejativaddhana, DS Briggs, R Thonglor
}

\begin{abstract}
Thailand has performed admirably in its health reform over the last few decades. Healthcare is provided at a relatively low cost and healthcare needs have transitioned to begin to address diseases and mortality of developed countries. The challenges now faced by Thailand are similar to most developed countries reflecting adult mortality and risk factors of an uppermiddle income population and the need to modify institutional structures to reflect these changing circumstances.
\end{abstract}

The approach to these challenges has focused on the implementation of knowledge based health development' and critically identifies 'the triangle that moves the mountain' (health reform) as a movement that mobilises; the creation of relevant knowledge, social movement and political involvement' to address 'inter-connected, complex and extremely difficult to solve' problems. The move to District Health Systems as the access point to healthcare and the service delivery structure demands competent qualified leadership and management. It requires an understanding of the differences in managing professionally dominated complex adaptive systems compared to traditional approaches of managing within bureaucratic structures.

This can be best described as managing connected, integrated care focused both on individuals as patients and communities with a strong emphasis on primary healthcare, prevention and evidence-based practice. It also requires an understanding of how distributed networks of practice (DNOP) provide the potential for researchers, practitioners and other agencies and communities to collaborate, learn and improve healthcare across geographic, jurisdictional and organisational boundaries.

This approach provides recognition of the need to build the capacity and capability of health professionals in the management and leadership of health systems and Thailand is moving towards this goal in implementing specific health systems management curriculum which focuses on action-based research and learning together at the District health level augurs well for continued ability to address current health challenges and to achieve SDGs.

Abbreviations: DHS - District Health System;

DNOP - Distributed Networks of Practice; HSRI - Health Systems Research Institute; MoPH - Ministry of Public Health; NHSO - National Health Security Office; SDG - Strategic Development Goal; UHC - Universal Health Coverage.

Key words: health systems management; action-based research; action-based learning; district health systems; distributed networks of practice.

\section{Phudit Tejativaddhana}

College of Health Systems Management (NUCHSM)

Naresuan University, Phitsanulok, Thailand.

\section{David S Briggs}

College of Health Systems Management (NUCHSM)

Naresuan University, Phitsanulok, Thailand.

\section{Romnalin Tonglor}

Faculty of Public Health

Naresuan University, Phitsanulok, Thailand.

Correspondence:

phuteja@gmail.com <phuteja@gmail.com> 


\section{Introduction}

Thailand has performed admirably in its health reform over the last few decades and is performing better than many low to middle income countries. [1] Healthcare is provided at a relatively low cost and healthcare needs have transitioned to begin to address diseases and mortality of developed countries, including that of an ageing population. Traditionally, Thailand is portrayed as having a majority rural demography but urban-based populations now equal that of the rural population. Thailand has been proactive in the transitioning of the delivery and quality of healthcare, engaging citizens at the village level as the first line of care, as health volunteers and promoting primary healthcare as the entry point to health services, with a focus on health promotion and prevention while also implementing universal healthcare, at a time of low fiscal growth. [1-4] Further detail about Thailand is described in Figure 1 below.

\section{Figure 1: Thailand at a glance 2014}

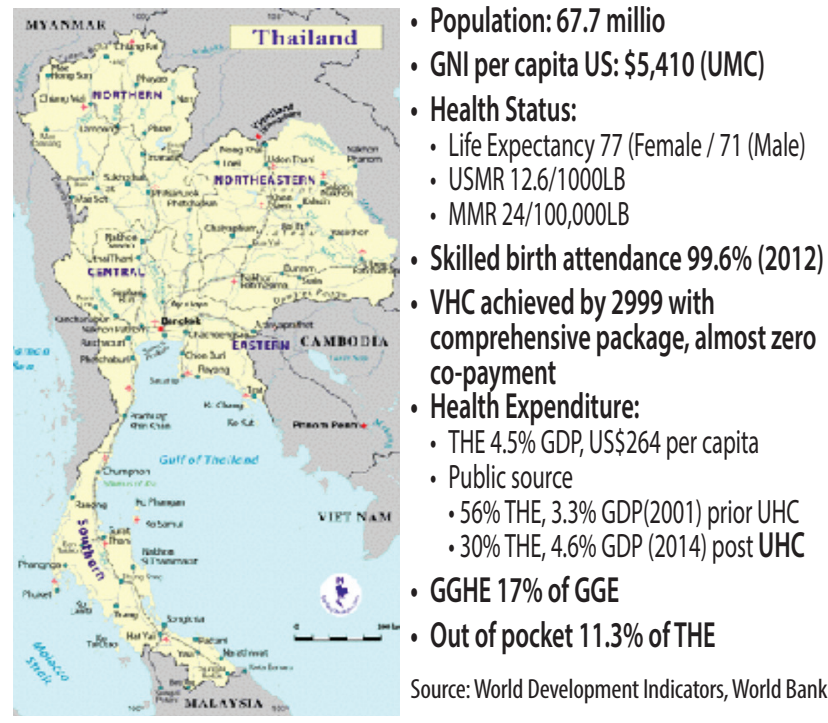

Source: Tangcharoensathien (2016) [5]

Note: $\mathrm{UHC}=$ Universal Health Coverage; THE = Total Health Expenditure; $\mathrm{GGHE}=$ Government General Health Expenditure; GGE $=$ Government General Expenditure.

The challenges now faced by Thailand are similar to most developed countries; an ageing and increasingly urban population reflecting adult mortality and risk factors of an uppermiddle income population and modifying institutional structures to reflect these changing circumstances. [14] Much has been done at the Macro level to restructure institutional arrangements through the changing role of the Ministry of Public Health (MoPH). While the Ministry remains the national health authority it is now supported and capacity strengthened by other autonomous health agencies such as the Thai Health Promotion Foundation, the National Health Commission tasked with participatory engagement of all actors in the development of public policy and the Emergency Medical Institute of Thailand. [2]

Of particular note in these structural changes, the National Health Security Office (NHSO) was mandated to manage Universal Health Coverage (UHC), strategic purchasing, payment mechanisms and has been credited with 'strong institutional capacity in improving health systems efficiency and equitable access.' [2, p.5] Likewise the Health Systems Research Institute (HSRI) has responsibility to build capacity in health systems research and it is credited as being successful in the health reform process 'by generating knowledge and increasing policy makers demand for high quality evidence to guide decision making.' [2, p.5] Wasi describes the 'implementation of knowledge based health development' as critical and identifies 'the triangle that moves the mountain' (health reform) as a movement that mobilises; the creation of relevant knowledge, social movement and political involvement' to address 'interconnected, complex and extremely difficult to solve' problems. [6, pp 2-3]

Beneath this overarching institutional arrangement Thailand settled in 2012 on the concept of the structure of the district health system (DHS) that extends beyond health services to other social services and community actions. The DHS is the entity that provides access and delivers health services to local communities, in order to improve health and quality of life. [7] In its extensive networks of Provinces there are hospitals and health structures of a relatively good standard within some 700 districts that have responded well in reducing the prevalence of communicable diseases. However, the Thai health system has been described as being 'in crisis' because of the exponential increase in health expenditure over income and, the need to restructure the system to address the increasing burden of chronic diseases in an increasingly urbanised context. [6, p.6] This means moving towards a 'good health orientated system,' which 'guarantees access to adequate quality healthcare for all'. [6, p.6]

This DHS policy direction has been formulated from best practices observed from several pilot projects on community health development in districts during the past decade. [8,9] This approach is claimed as one of the successful exemplars of 'bottom-up movement' for healthcare reform in Thailand. [8] The main concept of this policy is relevant to the concept and principle of the WHO's DHS development based on primary healthcare as specified in the Harare Declaration signed in 1987. [10] The purposes of this policy are to 
improve quality of life of people and to encourage people to have better self-care and to look after each other in their own communities. The policy aims to improve people's health status through better management of their own health and for people to have better capacity to deal with changing health challenges, and to reduce the cost of medical care. [11]

The policy aims to have stronger collaborative health networks to build a healthy district and to better respond to new health challenges while improving quality health services at a standard level and, improved patient's satisfaction and health professionals' happiness in their daily work. Finally, this policy focuses on strengthening primary care with better quality. [11]

The DHS is a collaborative working system for health by every sector, not just the health sector in the district. Its management style is specific to the context of each district and there should be sharing of resources within the districts. The way of working together should be through appreciation and using knowledge management. This approach should support people and communities in the district to be selfreliant and help each other as 'no one will be left behind'. The districts should have a common goal 'for the health of the people'. [12, p.10]

The district level of administration is regarded as the most appropriate level for improving health of people and communities for the following reasons:

1) It is an appropriate level to bridge between health policy and implementation.

2) It is so close to people and community that it can understand local health needs and can make local health policies and development plans to fit with the needs of local people;

3) It is an appropriate level to have effective cooperation and distribution of health resources such as health personnel, budget, medical supplies and materials, academic support, and use of health information by all stakeholders in the district.

4) It can use these resources with coverage and equity as well as modifying to meet relevant local needs;

5) It can encourage intersectoral actions and participation of all sectors including the people sector in health and social development systematically. Also, these sectors can both be involved in governance and management of health systems and health services. [11,12]

The move from managing hospitals, health centres, and a focus on public health approaches is a significant challenge for all health systems wanting to shift the focus from illness and the dominant role of the acute care sector. Managing health systems requires different understanding and skills from that previously required and can be described as managing connected, integrated care focused both on individuals as patients and communities with a strong emphasis on primary healthcare, prevention and evidencebased practice. [13]

This approach suggests at the service delivery level, a move from centralised bureaucratic governance and management, typical of most health systems to professional dominated bureaucracies and then to managing professionally dominated, complex adaptive systems, $[14,15]$ that can be described as distributed networks of practice (DNOP). [16-18] The move from centralised bureaucracies to decentralised forms dominated by multiple professions also takes into account a growing recognition of the need for effective local engagement in healthcare delivery (localism) and the importance of the principle of subsidiarity in the public sector that suggests that 'government should only fulfil a subsidiary function for those tasks that cannot adequately be dealt with by lower tiers.' [19, p.11] This approach therefore requires that health managers need to be located at the point where services they are accountable for are delivered. [20]

There has been considerable research about the skills and capabilities required of health managers to respond to this transition in their roles. [21,22] Traditional bureaucratic approaches to management and organisational approaches focused on clearly defined organisational roles and structures, being knowledgeable, making decisions and controlling the staff and organisations. Subsequent to health systems experiencing constant change and becoming responsive to continuous health reform the focus has moved to engagement and relationship building ahead of concerns about structure and control, towards accepting that context is complicated and that health systems are complex, but also adaptive, and that in managing health systems we must concentrate on making sense of diverse competing interests, learn from the experiences, improvise, reflect and think about the future. [22]

This requires a change in management capability and skills towards greater emphasis on leadership, managing and making sense of change, managing self as well as people, communicating, motivating, engaging and, in making decisions and having a greater focus on strategic thinking, clinical governance and the quality of care and service. [22] Therefore, the change to DHS as the basis for service 
delivery is not just about changing structure but extending the boundaries to include the social sector. It is also about changing the way health professionals think, manage, lead and engage in effective delivery of service within a DHS structure. The policy of moving towards DHS as the entry point to access service delivery has been well developed and documented by the $\mathrm{MoPH}$ in recent times $[11,12,23]$ and the inherent challenges of establishing DHS structures have been evident for some decades [10] but researched more recently in the Thai context by Tejativaddhana and colleagues. [24]

The need to develop the capability and capacity of health professionals to effectively manage district health systems has been recognised by the $\mathrm{MoPH}$ and training opportunities for this purpose have been ongoing. Naresuan University, to its credit has for some time been perceptive about the need to shift the focus of those who manage and lead health systems towards managing health systems with curriculum content consistent with that available in most developed countries where health management is recognised as a profession and tertiary programs are available based on specific health management curriculum.

In 2006 the Thai-Australian Alliance, a collaboration between Naresuan University and the University of New England and the Ministry of Public Health Thailand ${ }^{1}$ was asked by the MOPH and the NHSO to 'identify competencies and skills for a health management curriculum for health professionals working in primary healthcare in rural Thailand.' [25] This Alliance also consolidated five years of health management collaboration by conducting the First International Conference of Health Service Delivery Management in Phitsanulok, Thailand in October 2009. This conference conducted over four days with 450 delegates from 17 countries and 14 organisations with the organisers intending that an outcome of the conference would be 'a heightened awareness in the Asia Pacific of the importance of health management...as a profession in its own right.' $[26$, p.26] This outcome was achieved by all those present through the 'Phitsanulok Declaration' endorsed at that conference. [26, p.29]

This significant contribution in recognising the importance of well-trained health managers in managing complex

\footnotetext{
${ }^{1}$ This Alliance included through memorandums of understanding the Australasian College of Health Services Management (ACHSM) and the Society of Health Administration Programs in Education (SHAPE). ACHSM is the professional College of health managers and SHAPE represents tertiary health management providers, mostly located in Australian universities.
}

health systems and delivering quality healthcare is being further enhanced by the leadership of Naresuan University together with the MoPH with the current establishment of The College of Health Systems Management (NUCHSM) at Naresuan University. This College, supported by an International Advisory Faculty of Health Management expertise and Thai experts are about to commence post graduate health systems management courses by coursework and by research. [27] This program will attract health professionals having a leadership and management role in the DHSs, policy analysts and researchers in Thailand and from the sub-region.

The emphasis of the learning approach will be action-based participatory research addressing the real challenges of ever changing health systems and their continuous evolution. Contiguous with this initiative the MoPH has announced funding aimed at improving local district health systems and the health and quality of life of Thai people. The first initiative, involving the central agencies described earlier will focus on improving the DHS capability to govern through District Health Boards and to organise services more effectively. [28] The second initiative is to establish and strengthen the concept of primary care clusters within smaller identifiable populations to provide comprehensive multidisciplinary teams services 30,000 populations with the inclusion of a family doctor per 10,000 people. [29]

In concert with these initiatives the Thai Health Promotion Foundation has funded a two-year project aligning five DHS with an academic research/consultancy team to form a learning network focused on improving the DHS to achieved the Sustainable Development Goals (SDGs) with an emphasis on SDG 3 - 'Ensure healthy lives and promote wellbeing for all ages'. [30, p.2] This project of which NUCHSM and selected Districts are active participants will see health professionals working together to strategically plan the achievement of SDG 3 and to determine how to expand the knowledge and learning gained from the project to other districts, building capacity and capability. The emphasis will be on shared learning ensuring training and the translation of knowledge across geographic areas utilising technology and the notion of distributed networks of practice. The expected results of the project are innovations in managing district health systems to improve healthcare which will focus more on health promotion and well-being of the target populations which are relevant to the SDG 3. [31] 


\section{Conclusion}

Thailand has demonstrated a unique understanding of the challenges the Thai health system has faced and continues to face. It has been innovative in its engagement of its people and their communities. It has shaped changes at the national level on the basis of quality research that has led to good public policy. It has provided solid commitment to UHC as the main principle of that research and policy. It is clearly committed to the concept of DHS as the entry point and service delivery level for health services to social services and greater focus on SDGs. It now sees the current challenges as the urbanisation of population, the ageing of the population and the imperative of restraining health expenditure mainly through improved use of resources, using evidenced based practice to improve the effectiveness of care through a focus on achieving SDG 3.

Importantly it recognises that effective capability in managing health systems extending the concept of DNOPs as an approach building capacity through research and action, learning together, and to underpin a complex adaptive systems ability to respond to and address the critical management issues of the Thai health system.

\section{References}

1. Balabanova D, McKee M, Mills A, editors. Good health at low costs' 25 years on. What makes a successful health system? London School of Hygiene and Tropical Medicine; 2011.

2. Tangcharoensathien V, Pitayarangsarit W, Patcharanarumol. Achievements and challenges. Policy Note -Thailand Health System in Transition. Asia Pacific Observatory on Health Systems and Policies. Health Systems Review: World Health Organisation; 2016.

3. Prakongsai $P$, Limwattananon S, Tangcharoensathien V. The equity impact of the universal coverage policy: Lessons from Thailand. In: Chernichovsky D, Hanson K, editors. Innovations in health system finance in developing and transitional economies. London: Emerald Group Publishing; 2009, pp 57-81.

4. Tangcharoensathien $\mathrm{V}$, Pitayarangsarit W, Patcharanarumol W, et al. Promoting universal financial protection: how the Thai universal coverage scheme was designed to ensure equity. Health Res Policy Syst. 2013;11(25):1-9. DOI: 10.1186/1478-4505-11-25.

5. Tangcharoensathien V. Thailand UC Scheme: achievement and challenges [accessed 8 Oct 2016]. Presentation at Health Systems Management: Health Security and Financing Management for Better Health Equity Seminar. National Health Commission Office. Bangkok. Thailand. 26th August 2016. Available from http://chsm. nu.ac.th/en/2016/?p=454

6. Wasi P. Triangle that moves the mountain and health systems reform movement In Thailand. Nonthaburi Thailand: Health Systems Research Institute; 2000.

7. Boonyapaisalcharoen T. Preface. In: Saelee D, Rojanawipat K, Hungsapuek S, Tiptaengtae Sh, Tonsuthepweerawong C, Yana T, editors. Primary care value added with DHS (in Thai). 1st ed. Bangkok: National Health Security Office. 2014.
8. Archananuparp S. Preface. In: Saelee D, Tiptaengtae Sh, Tonsuthepweerawong C, Yana T, (eds). Karn Kub Kluen Rabob Sookkapab Amphur Chabub Prated Thai (The Movement of District Health System, Thailand version) (in Thai). 1st revised ed. Nondhaburi: Ministry of Public Health; 2014.

9. Tejativaddhana, P. Capacity building for District Health Systems Management Network to achieve health promoting districts [accessed 8 Oct 2016]. Presentation at ACHSM Annual Congress 2014. Adelaide, Australia. 2014. Available from: http://chsm.nu. ac.th/en/2016/?p=363

10. WHO. The challenge of implementing district health systems for primary healthcare [accessed 8 Oct 2016]. WHO/SHS/DHS. Geneva. 1988. Available from: http://www.ais.up.ac.za/med/pcm870/ challenge.PDF

11. Why district health systems should be strengthened. In: Saelee D, Namtadsanee S, Tiptaengtae Sh, Sumamal T, Tonsuthepweerawong C, Yana T, editors. Karn Kub Kluen Rabob Sookkapab Amphur Chabub Prated Thai (The Movement of District Health System, Thailand version) (in Thai). 1st ed. Nondhaburi: Ministry of Public Health; 2014. p. 4.

12. Saelee D, Tiptaengtae Sh, Tonsuthepweerawong C, Yana T, editors Karn Kub Kluen Rabob Sookkapab Amphur Chabub Prated Thai (The Movement of District Health System, Thailand version) (in Thai). 1st revised ed. Nondhaburi: Ministry of Public Health; 2014. p. 4.

13. Ferlie W. Systems and organisations. Public management 'reform' initiatives and the changing organisation of primary care. London J Prim Care. 2010; 3:76-80.

14. Anderson R, Issel L, McDaniel R. Nursing homes as complex adaptive systems: relationships between management practice and resident outcomes. Nurs Res. 2003;52(1):12-21.

15. Anderson RA, McDaniel RR. Managing healthcare organisations: where professionalism meets complexity science. Health Care Manage Rev. 2000; 25(1):83-92.

16. Jeffares $S$, Skelcher C. Democratic subjectivities in network governance: a $Q$ methodology study of English and Dutch public managers. Public Administration. 2011. 89(4):1253-1273 (/doi/ 10.1111/padm.2011.89.issue-4/issuetoc). Available from: http:// onlinelibrary.wiley.com.ezproxy.une.edu.au/doi/10.1111/j.1467.

17. Van den Hooff B, van Weenen F, Soekijad FM, Huysman M. The value of online networks of practice: the role of embeddedness and media use. Journal of Information Technology. 2010; 25(2):205-215.

18. Hustad E A. Conceptual Framework for Knowledge Integration in Distributed Networks of Practice [accessed 8 Oct 2016]. Proceedings of the 40th Hawaii International Conference on Systems SciencesIEEE Computer Society 2007. Available from: http://www. computer.org/portal/web/csdl/doi/10.1109/HICSS. 2007.10

19. Hartwich O. A global perspective on localism [accessed 8 Oct 2016]. Occasional Paper. Wellington: The New Zealand Initiative and Local Government New Zealand; 2013. Available from: http://nzinitiative. org.nz/site/nzinitiative/files/publications/Global\%20 Perspective\%20on\%20Localism.pdf

20. Briggs D.S. SHAPE Declaration on the Organisation and Management of Health Services: a call for informed public debate. Asia Pac J Health Manag. 2008;3(2)0.

21. Taytiwat, P, Briggs D, Fraser J, Minichiello V, Cruickshank M. Lessons from understanding the role of community hospital director in Thailand: clinician versus manager. The Int J of Health Plann Mgmt. 2010. DOI: 10.1002/hpm.1040.

22. Briggs DS, Smyth A, Anderson JA. In search of capable health managers: what is distinctive about health management and why does it matter? Asia Pac J Health Manag. 2012:7(2). 
23. Wiriyapongsukit $S$, Mungchit $P$, Namtatsanee $S$, editors. District Health System: Thailand movement version (in Thai). 2 nd ed. Nondhaburi: Ministry of Public Health; 2013.

24. Tejativaddhana P, Briggs DS, Fraser J, Minichiello V, Cruickshank M. Identifying challenges and barriers in the delivery of primary healthcare at the district level: a study in one Thai province. The Int J of Health Plann Mgmt. 2012.DOI: 10.1002/hpm.2118.

25. Yanggratoke $S$, Briggs DS, Alexander C, Taytiwat $P$, Cruickshank M, Fraser J, Ditton M, Gaul M. The Thai- Australian Alliance: Developing a Rural Health Management Curriculum by Participatory Action Research. World Health Popul. 2010;11(3).Vol 11(3).

26. Briggs DS, Tejativaddhana P, Kitreerawutiwong N. Health Declarations. Asia Pac J Health Manag.2010:5(1).

27. Tejativaddhana P, Briggs DS. The establishment of College of Health Systems Management, at Naresuan University, Thailand [accessed 8 Oct 2016]. 2016. Available from http://chsm.nu.ac.th/en/ $2016 / ? p=367$

28. Bureau of Information, Ministry of Public Health. Four organizations hand in hand to improve quality of life of people by using areabased and participation of all sectors approach (in Thai) [accessed 8 Oct 2016]. 30 March 2016. Ministry of Public Health. 2016.

Available from: http://pr.moph.go.th/iprg/include/admin_hotnew/ show_hotnew.php?idHot_new $=81337$

29. Ministry of Public Health. Guideline on the Operation of Primary Care Cluster for Health Providers (in Thai) [accessed 8 Oct 2016]. Nondhaburi, Ministry of Public Health. 2016. Available from: http://bps.moph.go.th/new_bps/sites/default/files/Guidelines\% 20PCC.pdf 30. WHO. 2016. From MDGs to SDGs. A new era for global public health 2016-2030 [accessed 8 Oct 2016]. Available from: http://www.who.int/about/financesaccountability/funding/ financing-dialogue/MDGstoSDGs_Summary.pdf?ua=1

31. Tejativaddhana P. The research proposal on development of prototype districts to pass on the effective district health systems management to other districts towards the achievement of SDGs (in Thai) [accessed 8 Oct 2016]. College of Health Systems Management, Naresuan University; 2016. Available from: http:// chsm.nu.ac.th/en/2016/?p=451 